\title{
SINERGISITAS PEMERINTAH DAN MASYARAKAT DALAM UPAYA PENGEMBANGAN DESA WISATA \\ (Studi Di Desa Wisata Adat Suku Osing Kemiren Kecamatan Glagah - Banyuwangi)
}

\author{
Agista Ul Hakim Paxi Permadi ${ }^{1)}$ \\ Prodi Ilmu Pemerintahan, FISIP Universitas Muhammadiyah Jember \\ Jl. Karimata No.49 Jember Kode Pos 69121 \\ Email : gistapaxi@gmail.com \\ Emy Kholifah $\mathbf{R}^{2)}$ \\ Prodi Ilmu Pemerintahan, FISIP Universitas Muhammadiyah Jember \\ Jl. Karimata No.49 Jember Kode Pos 69121 \\ Email : emykholifah25@gmail.com
}

\begin{abstract}
This study aims to describe the synergy of the Government and the Society in affording to develop the Tourism Village (Study on the Tribal Tourism Village of Osing Kemiren Glagah Sub-district of Banyuwangi Regency) which covers the Central, Regional and Village Governments. The study describes the form of cooperation or synergy between the Government and the community in developing the Tourism Village Adat Kemiren. The research method uses qualitative approach. Source of data in obtaining primary and secondary data isby means of doing interview, observation, and documentation by using purposive sampling. The analysis uses interactive datamodel which covers the data collection, the data reduction, data presentation, and data verification. The synergic involvementbetween government and society in an effort to develop the Kemiren Traditional Tourism Village consists of three forms of synergy: (1). Synergy of Policy on Tourism Village from Central Government to Village Government; (2). The synergy of Local Community about human resources empowerment, as well as the implementation of policies which have been made (3). The synergy of community toward self-reliance activities, that is a tradition of the Osing Society atthe Kemiren village which is initiated by the District Government to be the Annual Festival Agenda being promoted to tourists.By the existence of three forms of synergies, the Government and the Society have tried to develop the Tourism Village for the sake of community welfare, empowering the community and directly involved in order to be economically and socially feltdue to the development of village tourism.In its implementation of village tourism development involves many organizations, such as Karang Taruna and Pokdarwis at Kemiren village as well as the other youths involvement
\end{abstract}

Keywords: Synergy, Village Tourism Development. Government and Society

\begin{abstract}
ABSTRAK
Penelitian ini bertujuan mendeskripsikan tentang Sinergisitas Pemerintah dan Masyarakat dalam Upaya Pengembangan Desa Wisata (Studi Di Desa Wisata Adat Suku Osing Kemiren Kecamatan Glagah Kabupaten Banyuwangi) yang meliputi Pemerintah Pusat, Daerah, dan Desa serta mendeskripsikan bentuk kerjasama atau sinergisitas Pemerintah dengan masyarakat dalam mengembangkan Desa Wisata Adat Kemiren. Metode penelitian menggunakan pendekatan kualitatif. Sumber data di peroleh data primer dan sekunder. Penggumpulan data melalui wawancara, observasi, dan dokumentasi menggunakan purposive sampling. Analisis menggunakan analisis data model interaktif yang meliputi, Pengumpulan Data, Reduksi Data, Penyajian Data, dan Verifikasi Data.Dalam sinergisitas pemerintah dan masyarakat dalam upaya pengembangan Desa Wisata Adat Kemiren terdapat 3 bentuk sinergisitas:(1). Sinergisitas Kebijakan tentang Desa Wisata dari Pemerintah Pusat sampai
\end{abstract}


kepada Pemerintah Desa (2). Sinergisitas Pemeberdayaan Masyarakat Lokal tentang SDM dan juga merupakan bentuk implementasi dari kebijakan yang telah dibuat (3). Sinergisitas kegiatan swadaya masyarakat yang merupakan kegiatan tradisi Masyarakat Osing di Kemiren dan digagas oleh Pemerintah Daerah Kabupaten untuk menjadi agenda Festival tahunan agar dapat dipromosikan kepada wisatawan. Dengan adanya tiga bentuk sinergistas, bahwa Pemerintah dan Masyarakat telah berupaya untuk mengembang Desa Wisata untuk kesejahteraan masyarakat serta diharapkan dapat memberdayakan masyarakat dan melibatkan secara langsung agar dapat merasakan pembangunan Kepariwisataan, didalam pelaksanaanya melibatkan banyak organisasi seperti Karang Taruna dan Pokdarwis di Kemiren sebagai pemuda dan terlibat secara lansung.

Kata Kunci: Sinergisitas,Pengembangan Desa Wisata. Pemerintah dan Masyarakat

I. PENDAHULUAN

Pengembangan pariwisata Indonesia telah tercermin dalam rencana strategis yang dirumuskan oleh Kementrian Kebudayaan dan Pariwisata RI, yakni (1) meningkatkan kesejahteraan masyrakat dengan membuka kesempatan berusaha dan lapangan kerja serta pemerataan pembangunan di bidang pariwisata (2) mewujudkan pembangunan pariwisata yang berkesinambungan sehingga memberikan manfaat social-budaya, sosial ekonomi bagi masyarakat dan daerah, serta terpeliharanya mutu lingkungan hidup (3) meningkatkan kepuasan wisatawan dan memperluas pasar, dan (4) menciptakan iklim yang kondusif bagi pembangunan pariwisata Indonesia berdayaguna, produktif, transparan, dan bebas $\mathrm{KKN}$ untuk melaksanakan fungsi pelayanan kepada masyarakat, dalam institusi yang merupakan amanah yang dipertanggungjawabkan.

Pandangan Kementrian kebudayaan dan pariwisata RI, bahwa pengembangan pariwisata Indonesia harus didahului dengan pemahaman mengenai berbagai tantangan dan hambatan yang harus dihadapi dalam merencanakan dan melaksanan pengembangan pariwisata. Dalam hal pembangunan kepariwisataan ditegaskan dengan adanya dasar hukum pengembangan pariwsata sesuai dengan prinsip pengembangan adalah undangundang RI Nomor 10 Tahun 2009 tentang Kepariwisataan tentang pembangunan kepariwisataan (pasal 6: pembangunan kepariwisataan dilakukan berdasarkan asas sebagaimana dimaksud dalam pasal 2 yang diwijudkan pelaksanaan rencana pembangunan kepariwisataan dengan memperhatikan keanekaragaman, keunikan, dan kekhas budaya dan alam , serta kebutuhan manusia untuk berwisata, pasal 8: 1).

Kabupaten Banyuwangi sebagai salah satu ODTW (obyek daya Tarik wisata ) di Jawa Timur telah menetapkan didalam RPJM Tahun 2016-2021dan RPJP Tahun 2010-2025 sebagai dasar pembangunan Kabupaten Banyuwangi tentang arah kebijakan pengembangan pariwisata, sebagai berikut:

a. Peningkatan pendapatan anggota masyarakat melalui kepariwisataan.

b. Pengembangan sektor pariwisata sebagai salah satu sumber penerimaan pendapatan daerah.

c. Peningkatan kemampuan anggota masyarakat untuk dapat memperoleh manfaat yang besar bagi kegiatan pariwisata.

d. Terwujudnya masyarakat sadar wisata melalui sapta pesona, 
sehingga tercipta suasana yang mendukung dan menunjang semakin berkembangnya usaha dan kegiatan kepariwisataan.

Sebagai salah satu daerah destinasi wisata di Jawa Timur, Kabupaten Banyuwangi memiliki banyak obyek wisata yang menarik untuk dikembangkan, seperti wisata alam, wisata sejarah, wisata seni dan budaya atau wisata lainnya. Akan tetapi ada salah satu wisata yang berbeda ketika para wisatawan berkunjung ke Kabupaten Banyuwangi dari Kabupaten sebelum-sebelumnya yang tidak hanya sekedar menyajikan keindahan alamnya saja namuh lebih kepada interaksi masyarakat. Oleh karena itu sudah berkembang jenis wisata minat khusus, yaitu wisata alternatif yang disebut desa wisata adat suku osing yang terletak di Kemiren Kecamatan Glagah berjarak 5 km dari pusat pemeritahan Kabupaten dan 2 $\mathrm{km}$ dari pusat pemeruntahan kecamatan. Desa wisata disini menawarkan kegiatan wisata yang menekankan pada unsur-unsur pengalaman dan bentuk wisata aktif yang melibatkan wisatawan berhubungan lansung dengan masyarakat setempat. Dengan ciri menonjolkan kelokalan budaya diharapkan desa wisata ni mampu bersaing dengan tempat wisata lain.

Pengembangan desa wisata ini harus memperhatikan kemampuan dan tingkat penerimaan masyarakat setempat yang akan dikembangkan menjadi desa wisata tersebut. Hal ini dimaksudkan untuk mengetahui karakter dan kemampuan masyarakat yang dapat dimanfaatkan dalam pengembangan desa wisata: 1) tidak bertentangan dengan adat istiadat budaya masyarakat setempat; 2) pengembangan fisik yang diajukan untuk meningkatkan kualitas lingkungan desa; 3) memperhatikan unsur kelokalan dan keaslian;4) memberdayakan masyarakat desa; 5) memperhatikan daya dukung dan daya tamping serta berwawasan lingkungan.

Objek wisata ini menawarkan suasana alam pedesaan yang mengingatkan wisatawan akan nuansa alami dan tradisional serta budaya yang kental, Sebagai desa wisata yang berpotensi di kabupaten Banyuwangi, desa wisata adat suku osing di Desa Kemiren tentu saja telah memberikan kontribusi bagi masyarakat setempat dan yang terpenting meningkatkan kualitas hidup dari kemiskinan, sesuai dengan Program Nasional Pemberdayaan Masyarakat (PNPM) Mandiri No: PM.26/UM.001/MKP/2010 yakni meningkatkan keberdayaan dan kemandirian masyarakat, dan kelompok peduli setempat dalam menanggulangi kemiskinan di wialayahnya serta meningkatkan modal masyarakat seperti kesadaran kritis, potensi sosial dan budaya serta kearifan local.

Peran masyarakat dalam penentuan pengembangan desa wisata adat di Kemiren memerlukan perhatian khusus agar mampu bersaing dengan wisata lainnya dan mampu bertahan dengan adanya modernisasi dijaman seperti saat ini. Sehingga berdasarkan uraian tersebut maka dalam penelitian ini peneliti mengambil judul "Sinergitas Pemerintah Dan Masyarakata Dalam Upaya Pengembangan Desa Wisata Di Wisata Adat Kemiren Kecamatan Glagah Kabupaten Banyuwangi”. Dengan harapan mampu menghasilkan penelitian penelitian baru yang dapat menjadi acuan pada penelitian 


\section{METODE PENELITI AN}

Pada penelitian ini penulis menggunakan jenis penelitian kualitatif. Adapun dalam met ode yang digunakan sebagai acuan dalam penelitian iniadalah deskriptif. Metode deskriptif adalah studi untuk menemukan fakta dengan interprestasi tepat melukiskan secara akurat sifat sifat dari beberapa fenomena, kelompok atau individu, menent ukan frekuensi terjadinya suatukeadaan.

Penelitian ini dilaksanakandi Desa Wisata Adat Osing Kemiren Kecamatan Glagah Kabupaten Banyuwangi dan penelit $\mathrm{i}$ an ini dilaksankan pada tanggal 25 Februari 2018-sel esai.Metode pengumpulan data pada penelitian inimenggunakan metode obsevasi wawancara dan dokumentasi . Penelitian ini menggunakan metodeanalisis data teori Miles dan Huberman( 2007: 20)dengan mel alui tiga tahapan yaitu:

1. Reduksi data

2. Display data

3. Pengambilan kesimpulan dan verifikasi

\section{HASIL DAN PEMBAHASAN}

Jumlah penduduk Desa Kemiren 2491 orang yang terdiri dari 1230 orang laki-laki, dan perempuan 1261 orang, termasuk 894 orang kepala keluarga. Desa Kemiren telah ditetapkan sebagai desa adat suku osing yang sekaligus dijadikan cagar budaya untuk melestarikan budaya osing.Penelitian ini dilakukan di Desa Kemiren, Kec. Glagah, Kab. Banyuwangi. Kemiren adalah salah satu desa yang dijadikan desa wisata, terletak strategis di wilayah perjalanan menuju wisata Kawah Ijen, desa ini memiliki luas $117.052 \mathrm{~m} 2$ memanjang hingga $3 \mathrm{~km}$ yang di kedua sisinya dibatasi oleh dua sungai, Gulung dan Sobo yang mengalir dari barat ke arah timur. Desa yang berada di ketinggian 144 $\mathrm{m}$ di atas permukaan laut yang termasuk dalam topografi rendah dengan curah hujan $2000 \mathrm{~mm} /$ tahun sehingga memiliki suhu udara rata-rata berkisar $22-26^{\circ} \mathrm{C}$ ini memang cukup enak dan menarik dari sudut suhu udara dan pemandangan untuk wisata.

\section{Sinergistas Kebijakan Publik}

Dalam analisis kebijakan mengidentifikasi terhadap factor - factor penentuan dalam setiap tahapannya. Hal ini beragam masalah - masalah kebijakan untuk pengembangan Desa Wisata yang harus dilanjutkan oleh Pemerintah Pusat diimplementasikan aparat pemerintah dalam berbagai level, berikut adalah dasar hukum pemerintah pusat, daerah sampai pemerintah desa untuk menjalankan kebijakanya dalam pengembangan Desa Wisata Kemiren dimana setiap kebijakan saling berkaitan antara satu dengan yang lainya.

\section{Sinergisitas Pemberdayaan Masyarakat}

Lokal

1) Bantuan Kementrian Pariwata melalui PNPM Kepada Masyarakat Kemiren Pada tahun 2010 pertengahan Kementerian Pariwisata memberikan bantuan melalui PNPM Pariwisata berupa satu set alat music tradisional yang biasanya digunakan untuk mengiringi tari gandrung. Hal ini dilakukan oleh Kementerian pariwisata untuk mengapresiasi akan budaya dari masyarakat suku adat osing yang berada kemiren masih tetap terjaga, karna tari gandrung merupakan lambang/icon bagi kota banyuwangi. Bantuan alat-alat tersebut diterima langsung oleh 
kelompok masyarakat kesenian kemiren.

2) Peningkatan Kapasitas Usaha

Masyarakat Melalui Pengelolaan Homestay Desa Kemiren Dalam rangka meningkatkan kesejahteraan masyarakat Kementerian Pariwisata (Kemenpar) melalui homestay. Dukungan itu diwujudkan melalui pelatihan dan bantuan kepada pengelola Homestay Desa Kemiren Kecamatan Glagah Kabupaten Banyuwangi. Pelatihan pengelolaan homestay itu dilaksanakan pada tanggal 9-10 September 2017 hari sabtu sampai minggu. Ketua Tim Percepatan Homestay Kementrian Pariwisata Vitria Ariani ikut terjun langsung mengawal materi pelatihan Pengelolaan Homestay. Dan adapun bantuan yang diberikan berupa 55 Almari Pakaian, 55 Tempat sampah, 55 Cover Bad, 10 Tong Sampah, 6 Clossed dan 6 HT. Keseriusan dan antusias masyarakat Desa Kemiren dalam mengelola homestay dibuktikan dengan Beberapa pertanyaan yang dilontarkan Bapak Arief Yahya Menteri pariwisata terkait desa wisata dan Sapta Pesona bisa dijawab dengan baik oleh warga.

3) Workshop Percepatan Pengembangan Destinasi Wisata Perdesaan dan Perkotaan Pada bulan November, dalam rangka mengembangkan Destinasi Wisata di Perdesaan dan Perkotaan, Kementerian Pariwisata mengundang 10 ( sepuluh ) Patriot Desa Wisata untuk diberi bekal dan Pelatihan untuk pengembangan Desa Wisata, kegiatan ini merupakan hasil dari Rangkaian kegiatan Rakornas Pariwisata II-2017 dan kegiatan ini dilaksanakan pada hari kamis sampai jumat pada tanggal 28-29 November 2017 bertempat di Hotel Grand Cemara jalan Cemara No. 1 Jakarta Pusat. Dalam Workshop kali ini di nara sumberi langsung oleh Bpk. Lokot Ahmad Enda dan $\mathrm{Bu}$ Vitria Ariani dari Deputi bidang Pengembangan Destinasi dan Industri Pariwisata Kementerian Pariwisata dan di hadiri oleh Bpk. Supriyanto selaku Kaur Perencanaan yang mewakili pemerintah desa kemiren. Desa wisata digagas sejalan dengan karakter dan potensi desa di Indonesia, sebanyak 74.954 tersebar di seluruh nusantara, dengan 1.902 di antaranya sudah memiliki potensi untuk dikembangkan menjadi Desa Wisata.

4) Pelatihan Guide Kepada PemudaPemudi di Desa Kemiren,Pemerintah Desa Kemiren bersama Universitas 17 agustus Banyuwangi melaksanakan sosialisasi Pelatihan to be guide dalam upaya memperdayakan pemudapemudi agar lebih produktif menjadi pendamping wisatawan yang akan mengunjungi obyek wisata di desa wisata kemiren. Munculnya wisatawisata yang ada di desa tersebut merupakan salah satu potensi, asset, dan juga sumberdaya alam yang bisa dimanfaatkan untuk kesejahteraan masyarakat. Potensi wisata tersebut dapat dijadikan salah satu unit usaha BUMDesa sebagiamana ditulis dalam pasal 3 dalam peraturan desa nomor 3 tahun 2016 tentang pendirian, pengurusan dan pengelolaan, dan pembubaran badan usaha milik desa tujuan pembentukan BUMDes :

a) Meningkatkan pendapatan asli desa dalam rangka 
meningkatkan

kemampuanpemerintah desa dalam penyelenggaraan pemerintahan dan pembangunan sertapelayanan masyarakat.

b) Mengembangkan potensi Perekonomian di wilayah pedesaan untuk mewujudkan kelembagaan yang tangguh dalam memberikan pelayanan terhadap kebutuhan masyarakat .

c) Menciptakan lapangan kerja.

d) Mengoptimalkan pengembangan potensi Desa.

e) Mengentaskan Kemiskinan.

Kelompok sadar wisata (Mpok Darwis) yang saat ini menjadi pengelola obyek wisata di desa tersebut bisa menjadi salah satu unit usaha yang berfokus pada pengelolaan obyek wisata di kawasan desa wisata Kemiren tersebut dengan BUMDES menjadi induk lokomotif perekonomian di desa.

5) Pembuatan Amenitas dalam Pengembangan Desa Wisata KemirenPemerintah Desa Kemiren bersinergi dengan BUMDES untuk membuat unit usaha yang bernama Warung Kemangi yang biasa disebut Pesantogan Kemangi adalah salah satu usaha warung yang bernuansa tradisional namun berwawasan internasional. Pesantogan Kemangi sendiri memliki makna pesantogan adalah tempat singgah dan kemangi ialah kenangan manis di Banyuwangi. Meskipun masih tergolong usaha kecil atau menengah tetapi warung ini sangat banyak diminati para konsumen.

Berdasarkan ciri makanan khas osing, Warung Kemangi berawal pada tahun
2016 di Desa Kemiren, Pemerintah desa memberi pinjaman modal awal : Rp.8.000.000, Penyertaan modal dari pemerintahan desa pada Tahun 2015 serta memberi bantuan, Jenis bantuan yang pernah diterima yaitu 2 tikel Rumah Adat osing yang digunakan sebagai tempat usaha. BUMDES Kemiren sebagai pendiri sekaligus yang menaungi warung kemangi dimana yang mengelola adalah pemuda kemiren atau biasa yang disebut KARANG TARUNA MEKARSARI Desa Kemiren. adapun dalam pembagian hasil yakni $40 \%$ dari hasil laba akan diserahkan ke BUMDES, disisihkan 10\% untuk fakir miskin dan yatim piatu, untuk $50 \%$ nya diserahkan ke pesantogan kemangi. Dengan adanya warung kemangi menjadi salah satu pusat tempat keramaian di desa kemiren oleh wisatawan yang sering berkunjung untuk menikmati menu yang disajikan, dampak dari keramaian tersebut membuka lapangan kerja bagi beberapa masyarakat kemiren dari bekerja dan membuat makanan ataupun jajanan. Selain pesantogan kemangi BUMDesa memiliki Usaha Artshop yang memegang peranan dalam memajukan perekonomian Desa Kemiren. Selain sebagai salah satu alternatif lapangan kerja baru,Arsthop juga berperan dalam mendorong laju pertumbuhan ekonomi Desa Kemiren agar menjadi desa yang maju dalam mengembangkan usaha.Saat ini Artshop telah berkontribusi besar pada pendapatan desa. Usaha yang dikelola pemuda karang taruna desa kemiren yang dibina langsung oleh BUMDES 
(Badan Usaha Milik Desa ) Kemiren dan dikelola oleh para pemuda karang taruna desa kemiren. Artshop dan Sablon Kemangi ini berdiri sejak 20 Oktober 2015 yang beranggotakan 7 orang pemuda yang terdiri 4 laki-laki di bagian Sablon Kemangi dan 3 anggota perempuan di bagian Artshop Kemangi.

6) Sinergisitas Kegiatan Swadaya Masyarakat Kemiren.
a. Festival Barong Ider Bumi
b. Festival Ngopi Sepuluh Ewu
c. Tumpeng Sewu
d. Festival Jajanan Khas Desa Kemiren

Dengan adanya kegiatan keswadayaan masyarakat pemerintah daerah berhasil mempromosikan dan menaikan eksistensi Desa Wisata Kemiren namun hanya untuk mengeksplor nilai-nilai yang sudah ada dan nampaknya mulai ada penggerusan semata-mata diekspos untuk wisatawan dank arena untuk meningkatkan kunjungan wisatawan yang akan berujung pada pendapatan ekonomi tanpa berpedoman pada nilai tradisi.

7) Dampak Kebijakan dalam Sinergisitas Pemerintah dan Masyarakat dalam Upaya Pengembangan Desa Wisata Adat Suku Osing Kemiren.

a) Data Kunjungan Wisatawan Desa Wisata

\begin{tabular}{|c|c|c|c|c|}
\hline No & TAHUN & $\begin{array}{c}\text { WISATAWAN } \\
\text { DOMESTIK }\end{array}$ & $\begin{array}{c}\text { WISATAWAN } \\
\text { MANCANEGARA }\end{array}$ & TOTAL \\
\hline 1 & 2012 & 4287 & 26 & 4313 \\
\hline 2 & 2013 & 4312 & 37 & 4349 \\
\hline 3 & 2014 & 5163 & 32 & 5195 \\
\hline 4 & 2015 & 5317 & 39 & 5356 \\
\hline 5 & 2016 & 5368 & 43 & 5411 \\
\hline 6 & 2017 & 24442 & 65 & 24507 \\
\hline
\end{tabular}

Sumber: data dari Pokdarwis Kencana Kemiren, 2018

b). Hasil Pendapatan Dari Pariwisata

\begin{tabular}{|l|l|l|l|}
\hline No & Tahun & $\begin{array}{c}\text { Omzet Kas Desa dalam } \\
\text { Rupiah }\end{array}$ & $\begin{array}{c}\text { Pengelolaan BUMDes dalam } \\
\text { Rupiah }\end{array}$ \\
\hline 1 & 2015 & $\mathrm{Rp} \mathrm{72.000.000}$ & $\mathrm{Rp} \mathrm{6.000.000}$ \\
\hline 2 & 2016 & $\mathrm{Rp} \mathrm{78.000.000}$ & $\mathrm{Rp} \mathrm{7.500.000}$ \\
\hline 3 & 2017 & $\mathrm{Rp} 84.000 .000$ & $\mathrm{Rp} 9.000 .000$ \\
\hline
\end{tabular}

IV. KESIMPULAN

Berdasarkan hasil penelitian yang telah dikemukakan, maka peneliti menarik kesimpulan bahwa sinergistas pemerintah dan masyarakat dalam upaya pengembangan desa wisata di wisata adat suku osing kemiren Kecamatan Glagah Kabupaten Banyuwangi secara nyata terlaksana di desa kemiren, dimana pemerintah pusat yakni kementerian pariwsata dan pemerintah kabupaten 
banyuwangi dinas pariwisata dan pemerintah desa memeiliki cara tersendiri dengan tujuan yang sama untuk membina dan memberdayakan masyarakat serta merangkul seluru kalangan masyarakat untuk ikut secara langsung dan bersinergi dengan kepala adat, karang taruna, mpokdarwis, Bumdes, dan stakeholder dalam mengembangkandesa wisata kemiren sehingga terbentuknya paket wisata yang menambah atmostfer wisatawan dikemiren dan hasil sinergisitas ini terbukti dengan jumlah wisatawan yang hadir di desa kemiren bertambah setiap tahunnya. Hal ini sesuai perda Banyuwangi no. 1 tahun 2017 tentang desa wisata dimana tujuan pengembangan desa wisata sendiri dalam pasal 3 adalah untuk menyejahterkan rakyat seta terjalinya hubungan timbal balik wisatawan dengan masyarakat setempat agar terlibat secara langsung dalam pengembangan desa wisata.

\section{DAFTAR PUSTAKA}

Agustino, Leo. $2006 . \quad$ Dasar-Dasar Kebijakan Publik. Bandung: CV. Alfabeta. 2002.

Departemen Kebudayaan dan Pariwisata. Pembangunan Kawasan Unggulan Minat Khusus Petualangan Kalimantan Timur. Jakarta: Direktoral Jenderal Pengembangan Produk Pariwisata. 2001.

Indonesia. Departemen Kebudayaan dan Pariwisata. Program Pemberdayaan Masyarakat dan Penanggulangan Kemiskinan Melalui Sektor kebudayaan dan Pariwisata (PNPM) Pariwisata. 2008. Retrevied January, 20, 2018 from http://www.kemenpar.go.id/

Effendi, Tadjuddin Noer. Srategi Pengembangan Masyarakat:

\begin{abstract}
Alternatif Pemikiran Normatif, dalam Jurnal Sosial Politik, Fakulta Ilmu Sosial dan Politik Universitas Gajah Mada, Volume 3 No.2. 1999.
\end{abstract}

Indonesia. Undang-undang Nomor 10 Tahun $2010 \quad$ Tentang Kepariwisataan.

Menteri Kebudayaan dan Pariwisata. PM.26/UM.001/MKP/2010 Program Pemberdayaan Masyarakat Melalui Desa Wisata.

Pemerintah Daerah Banyuwangi. Perda No. 13 Tahun 2012 Mengenai Rencana Induk Pembangunan Kepariwisataan Kabupaten Banyuwangi.

Peraturan Daerah Banyuwangi. Perda No. 1 Tahun 2017 MengenaiDesa Wisata di Kemiren.

Bupati Bayuwangi. Keputusan Perbup No. 401 Tahun 1996 Tentang penetapan lokasi Desa Wisata di desa kemiren.

Indonesia. Undang- Undang Nomor 6 Tahun 2014 tentang Desa. Bab XII, pasal 97,Lembaga Adat.

Pemerintah Desa Kemiren. RPJMDes 2016-2018 